\title{
Sudden cardiac death and antipsychotics. Part 1: Risk factors and mechanisms
}

\author{
Nasser Abdelmawla \& Alex J. Mitchell
}

\begin{abstract}
Mortality from causes other than suicide is higher than expected in schizophrenia. Cardiovascular causes are most common, accounting for the majority of the $5 \%$ of sudden and unexpected deaths. Most cases have no clear explanation on post-mortem examination ('sudden unexplained deaths') and are thought to result from fatal arrhythmias. Prospective studies show that people with prolongation of the QT interval beyond $500 \mathrm{~ms}$ are at increased risk of serious arrhythmias such as ventricular tachycardia and torsade de pointes. In about 1 in 10 cases, the torsade is fatal. Most antipsychotics prolong the QTc interval in overdose but some prolong it even at therapeutic doses. Droperidol, sertindole and ziprasidone extend the QT interval by an average of 15-35 ms; quetiapine, haloperidol and olanzapine by $5 \mathrm{~ms}$, to $15 \mathrm{~ms}$. There is only an approximate relationship between QT prolongation and risk of sudden death, and the risk related to antipsychotics is thought to increase in people with pre-existing cardiac disease, those taking multiple QT-acting drugs and those taking antipsychotics at high dose for long periods. There is little evidence of an association with route of administration. More data are required to clarify to what extent people with mental health difficulties who die suddenly have pre-existing cardiac disease.
\end{abstract}

This is the first of two articles discussing antipsychotics and sudden cardiac death. The second, which will appear in the next issue of APT, will focus on the monitoring of patients and prevention of such deaths (Abdelmawla \& Mitchell, 2006).

Sudden unexplained death in individuals with mental health problems was first described in 1849 and a link with antipsychotic drugs was postulated 40 years ago (Reinert \& Hermann, 1960; Titier et al, 2005). Recently regulatory authorities in several countries have expressed concerns about a relationship between antipsychotics and the risk of QTc interval prolongation, serious arrhythmias and sudden cardiac death (Committee on Safety of Medicines, 1990; 1996; Royal College of Psychiatrists, 1997; National Institute for Clinical Excellence, 2004).

The granting of a licence in Europe or the USA has been prevented or delayed for several antipsychotics and others have been withdrawn. In 1990, the Committee on Safety of Medicines (CSM) in the UK reported 13 cases of sudden unexpected death associated with the use of pimozide. This led to its restriction to a maximum daily dose of $20 \mathrm{mg}$ and the recommendation of periodic electrocardiogram (ECG) monitoring of those receiving more than $16 \mathrm{mg}$ daily (Committee on Safety of
Medicines, 1990). In 1998, the CSM found evidence linking sertindole with 13 cases of serious but nonfatal arrhythmia (36 fatal cases were suspected), prompting Lundbeck to voluntarily suspend sale of the drug (Committee on Safety of Medicines, 1998). Interestingly, in 2001 it was reintroduced by the European Committee of Proprietary Medicinal Products on a named-patient basis. In 1998, following concerns over QTc prolongation, thioridazine, mesoridazine and droperidol received a black-box warning in the USA and ziprasidone received a lower bold-print warning. By the end of 2000, the deaths of 21 people prescribed thioridazine had come to the attention of the CSM (Medicines and Healthcare Products Regulatory Agency, 2000), leading to its restriction to second-line treatment of schizophrenia in people under the direct care of a consultant psychiatrist. Shortly afterwards droperidol was withdrawn from the market by the manufacturers. The launch of the atypical antipsychotic ziprasidone continues to be delayed in the UK because more than $10 \%$ of patients taking the drug developed modest QTc interval prolongation (Box 1). However, in one large series of patients taking ziprasidone, only 2 in 2988 individuals had QT intervals longer than $500 \mathrm{~ms}$ (Trenton et al, 2003).

Nasser Abdelmawla is a specialist registrar in psychiatry. He completed his $\mathrm{PhD}$ on psychopharmacology and has an interest in druginduced adverse effects. Alex Mitchell is a consultant in liaison psychiatry at Leicester General Hospital (Department of Liaison Psychiatry, Brandon Mental Health Unit, Leicester General Hospital, Gwendolen Road, Leicester LE5 4PW, UK. Tel.: +44 (0116) 2256218; e-mail: alex.mitchell@leicspart.nhs.uk) and author of the BMA prize-winning book Neuropsychiatry and Behavioural Neurology Explained. He is interested in the overlap of physical and mental disorders. 


\section{Box 1 QTc intervals}

The QTc interval measures the time between the start and end of electrical ventricular activity. It is obtained by correcting the QT for heart rate using a regression formula (e.g. Bazett, Friderica). See part 2 of this overview (Abdelmawla \& Mitchell, 2006) for further discussion.

Several authors have asked whether these restrictions are justified, arguing that the relative and absolute risks of serious adverse events are not clear from case reports or ECG changes alone (Dershwitz, 2002).

In this article we examine the possible mechanisms of antipsychotic-induced sudden death and the likelihood of serious adverse events in those with drug-induced ECG changes.

\section{What is meant by sudden death?}

Sudden death refers to the unexpected death of a person who has no known acutely life-threatening condition and yet dies of a fatal medical cause (Box 2). The incidence of sudden death in the population is about 400000 cases per year in the USA and perhaps 80000 per year in the UK (Maron, 2003).

\section{Box 2 Causes of sudden cardiac death}

- Coronary artery disease

- Ischaemic cardiomyopathy

- Non-ischaemic cardiomyopathy

- Hypertrophic cardiomyopathy

- Arrhythmogenic right ventricular cardiomyopathy

- Commotio cordis

- Sarcoidosis

- Amyloidosis

- Myocarditis

- Valvular heart disease

- Congenital heart disease

- Cardiac tumours

- Long QT syndrome

- Brugada syndrome (Box 3)

- Wolff-Parkinson-White syndrome (Box 3)

- Electrolyte abnormalities

- Thyrotoxicosis

- Pro-arrhythmia from anti-arrhythmic agents

- Cocaine

After Spector (2005)
Yet it is rare in psychiatric settings, primarily because of the relatively short periods of observation compared with the lifetime risk. Mehtonen et al (1991) found only 49 sudden deaths among 25000 people with psychiatric disorders followed for 3 years. Jusic \& Lader (1994) emphasised that most sudden deaths in psychiatric settings are unexplained by post-mortem examination.

A modest-sized study of 74 cases of sudden death from five psychiatric hospitals in the north-east of England over a 12-year period generated some useful epidemiological information (Reilly et al, 2002). Sudden death accounts for about $5 \%$ of all deaths in psychiatric hospitals. Around 20\% of sudden deaths of people with mental health problems occur in those under 65. Contrary to early fears, only very rarely do deaths occur during restraint, behavioural disturbance or shortly after rapid tranquillisation. Antipsychotics are the most commonly prescribed drug in reported cases of sudden death, but in this series of 74 deaths, $40 \%$ of the individuals were not prescribed antipsychotics at the time of the event. About a third of individuals have schizophrenia, a third have a mood disorder and a third have an organic diagnosis (such as delirium or dementia).

Witnessed accounts suggest that sudden death is heralded by abrupt loss of consciousness within $1 \mathrm{~h}$ of the onset of acute symptoms. The symptoms can be of chest pain, weakness or fatigue, and palpitation. If there are no witnesses, it has been suggested that the description of sudden death may be appropriate if an individual known to have been medically stable less than $24 \mathrm{~h}$ previously dies without clinical evidence of a cause of death (Myerberg, 1997; Priori et al, 2001). In the sudden death of young people, post-mortem examination reveals a pre-existing cardiac cause in most cases (often called sudden cardiac death). Yet in the majority of cases of sudden death of young people with mental health problems there is thought to be no structural abnormality, although no good postmortem series in psychiatric cases has been reported (Reilly et al, 2002; Maron, 2003).

In one of the few autopsy series of sudden cardiac death in 14 patients taking antipsychotics, Green (1988) reported the cause of death as 'chronic cardiac toxicity'. In a survey of autopsies associated with psychotropic medication in Finland, of the individuals who succumbed to sudden cardiac death despite structurally normal hearts, half had been entirely asymptomatic previously (Chugh et al, 2000). This suggests that arrhythmias are responsible in most cases rather than one of a myriad of other possible causes such as hypertrophic cardiomyopathy, commotio cordis (Box $3)$, coronary artery anomalies, ruptured aortic 
Box 3 Brugada and Wolff-Parkinson-White syndromes and commotio cordis

\section{Brugada syndrome}

This is an inherited form of cardiac arrhythmia, presenting with an ECG pattern of S-T segment elevation in leads V1-V3, and incomplete or complete right bundle branch block. In about $20 \%$ of cases, the underlying cause is a genetic defect in the SCN5A gene

Wolff-Parkinson-White syndrome

The syndrome is characterised by an abnormal band of atrial tissue which connects the atria with the ventricles and can electrically bypass the atrioventricular node. As this node and bypass tract have different conduction speeds and refractory periods, a re-entry circuit can develop, causing paroxysms of tachycardia

Commotio cordis syndrome

In commotio cordis a blunt non-penetrating impact to the chest causes cardiac arrest

aneurysm, myocarditis and valvular heart disease (Spector, 2005). The true distribution of initial arrhythmias is not known, since several minutes usually elapse between collapse and rhythm assessment. Engdahl et al (2002) reported that recordings obtained during spontaneous episodes of sudden cardiac death demonstrated ventricular arrhythmias in about $85 \%$ of cases.

\section{How common is antipsychotic- induced sudden death?}

\section{Mortality in people with schizophrenia}

There is an excess mortality rate (standardised mortality ratios for all causes of death are 1.7 times higher in men and 1.3 times higher in women) in people with psychiatric illnesses, even after allowing for the effect of suicide (Waddington et al, 1998; Ösby et al, 2000). This non-suicide elevated risk holds true for people with schizophrenia (Allebeck \& Wistedt, 1986; Brown et al, 2000) or depression (Saz \& Dewey, 2001), as well as for those with delirium and dementia. The standardised mortality ratio is greater than 2 for both males and females with schizophrenia (Hewer \& Rossler, 1997; Ösby et al, 2000).

The causes are complex and include an excess of physical health problems, an increased rate of vascular risk factors (smoking, lack of exercise, obesity, diabetes) and a lower than expected uptake of healthcare services (Nose et al, 2003; Connolly \& Kelly, 2005). However, the largest single cause is cardiovascular disease. When examined in detail, data show that people with schizophrenia have an increased incidence of arrhythmia, syncope and heart failure, diabetes and stroke (Curkendall et al, 2004).

Two major risk factors for excess mortality in psychiatric patients are medical comorbidity and treatment with antipsychotic medication. The latter is not necessarily causative, as higher doses might be linked with mortality through a confounding factor such as worse physical health in those with more serious mental health problems. Compared with the overall excess of non-suicide mortality, the number of deaths that might be attributable to medication is small, but most argue that iatrogenic mortality must be taken seriously, with appropriate steps taken towards prevention (Abdelmawla \& Mitchell, 2006).

\section{Mortality in patients prescribed antipsychotics}

Ray et al (2001) conducted a retrospective cohort study of half a million Medicaid patients in the US state of Tennessee between 1988 and 1993, before the introduction of atypical antipsychotics. They found that the risk of sudden death for individuals receiving antipsychotic drugs was 2.39 times that for 'non-users'. Montout et al (2002) conducted a 4-year prospective study of 3474 individuals with schizophrenia. The risk of 'all-cause' death and the risk of 'non-suicide cause' death was increased in users of thioxanthenes (alone or with other drugs) and atypical antipsychotics (odds ratio $\mathrm{OR}=2.06$ ). Hennessy et al (2002) retrospectively examined the rates of cardiac arrest and ventricular arrhythmia in people with treated schizophrenia and in nonschizophrenia controls in a cohort of 90000 obtained from three US Medicaid programmes between 1993 and 1996. The antipsychotics used included clozapine, haloperidol, risperidone and thioridazine. People treated for schizophrenia had higher rates of cardiac arrest and ventricular arrhythmia than controls. The relative risk for cardiac arrest and ventricular arrhythmia in those taking risperidone compared with haloperidol was 1.5 , but there was no dose-response relationship. Liperoti et al (2005) conducted a case-control study of residents of nursing homes in six US states. Use of conventional antipsychotics (but not atypical antipsychotics) was associated with a nearly twofold increase in risk of hospitalisation for ventricular arrhythmias or cardiac arrest, particularly in those with pre-existing cardiac disease. 


\section{Mortality following rapid tranquillisation}

Concern has been expressed regarding reports of sudden death after the emergency use of psychotropic medication. Although this is sometimes linked with rapid tranquillisation in the literature on acute behavioural disturbance, there have been no deaths or serious cardiovascular events recorded during several recent large trials involving the treatment of over 1500 patients with ziprasidone $v$. haloperidol, olanzapine $v$. haloperidol or midazolam $v$. haloperidol-promethazine mix (TREC Collaborative Group, 2003; Citrome et al, 2004)

In the Finnish study of 49 cases of sudden cardiac death (Mehtonen et al, 1991) none was associated with a struggle and most patients died in bed more than 4 days after admission, suggesting little relationship with acute behavioural disturbance. Indeed in the literature there are few cases of sudden death that are clearly linked with rapid tranquillisation itself as opposed to cumulative antipsychotic dosing.

Jusic \& Lader (1994) reported two such cases. In the first, a 31-year-old man died within minutes of being forcibly given intramuscular medication. High concentrations of fluphenazine decanoate were found in the heart, suggesting that the intramuscular depot was inadvertently given intravenously. In the second case, a 27-year-old man with schizophrenia was given intravenous haloperidol and diazepam at appropriate doses and suffered a cardiac arrest but showed no pathology at post-mortem examination. However, caution must be taken when interpreting post-mortem drug concentrations.

Altimari and colleagues, for the National Alliance for the Mentally Ill, compiled a list of 142 deaths over a 10-year period that had occurred while patients were in restraint or seclusion. From these and other data (National Alliance for the Mentally Ill, 1998), it is apparent that in some cases the mechanism of sudden death following rapid tranquillisation appears to involve inadvertent suffocation rather than a drug-related effect.

\section{ECG irregularties and mechanisms of sudden death}

Considerable research has attempted to clarify the underlying electrical substrate that predisposes individuals to ventricular fibrillation and sudden cardiac death. It is known that ventricular tachycardia degenerates first to ventricular fibrillation or torsade de pointes and then quickly to asystole.
Most work has concentrated on risk in those who have ischaemic heart disease or other causes of heart failure (Lane et al, 2005). In people with structurally normal hearts only a limited number of risk factors have been studied, and most evidence relates to electrocardiographic markers such as the QT interval (for further information see part 2 of this overview: Abdelmawla \& Mitchell, 2006).

\section{Torsade de pointes}

Although torsade de pointes is often a transient, selfcorrecting condition, in about a third of cases it leads to ventricular fibrillation and about 1 in 10 events cause sudden death (O'Brien \& Oyebode, 2003; Montanez et al, 2004). Torsade de pointes is largely unpredictable but certain risk factors can be identified (Box 4). Drug-induced torsade de pointes typically arises with the use of medications that cause QT prolongation beyond $500 \mathrm{~ms}$ at the same time as inducing polymorphic ventricular tachycardia (twisting changes in QRS morphology on the ECG) (Morganroth, 1993; Zareba \& Moss, 2003). Patients with QT prolongation are at particular risk if they have QT-related arrhythmias such as sudden bradycardia or long pauses (e.g. compensatory pauses after ventricular ectopy), enhanced U-waves, T-wave alternans, polymorphic ventricular premature beats, couplets or non-sustained polymorphic ventricular tachycardia. The management of torsade de pointes includes withdrawal of offending agents, empirical administration of magnesium regardless

Box 4 Risk factors for QT prolongation and torsade de pointes

- Older age

- Bradycardia

- Congenital long-QT syndrome

- Electrolyte abnormalities (especially hypokalaemia or hypomagnesaemia)

- Female gender

- Heart disease (especially left ventricular hypertrophy, ischaemia, or low left ventricular ejection fraction)

- Significant T-wave abnormalities

- Mutations of the sodium channel

- LQT3 mutations of the SCN5A sodium channel gene

- Mutations of the potassium channel gene

- LQT1 mutations of the KCNQ1 gene

- LQT5 mutations of the minK gene

- LQT2 mutations of the HERG gene

- LQT6 mutations of the MiRP1 gene 
of serum magnesium, correction of serum potassium to $4.5-5 \mathrm{mEq} / 1$ and manoeuvres to increase heart rate (isoprenaline or pacing) if necessary. However, prevention is probably the most important strategy for at-risk patients.

\section{Abnormalities of the QT interval}

Abnormalities in the QT interval can be divided into three types:

- prolongation of the interval

- differences in the interval across different ECG leads (QT dispersion)

- QT variability with time.

Only prolongation has been studied in any depth in relation to antipsychotics. Rate-corrected QT intervals (QTc) are usually around $400 \mathrm{~ms}$ in duration, and values lower than $440 \mathrm{~ms}$ are considered normal (Glassman \& Bigger, 2001); QTc values above $450 \mathrm{~ms}$ (men) or $460 \mathrm{~ms}$ (women) are considered prolonged. Thus, there is a borderline area of uncertain significance (Al-Khatib et al, 2003; Taylor, 2003). The cut-off point of $500 \mathrm{~ms}$ is widely accepted as indicating substantially higher risk of arrhythmias such as torsade de pointes (Botstein, 1993; Welch \& Chue, 2000; Glassman \& Bigger, 2001; Malik \& Camm, 2001). Progressive lengthening of the QT interval in repeated ECGs is a warning sign (Rautaharju \& Zhang, 2002). Broadly, the greater the QTc interval the higher the risk of torsade de pointes and other serious arrhythmias. Length of the QTC interval has been associated with risk of sudden death following myocardial infarction and congenital long-QT syndrome (Moss, 1993; de Bruyne et al, 1999). Evidence suggests that 5-10\% of people in whom drug-induced torsade de pointes develops harbour genetic mutations associated with long-QT syndrome (Dilaveris \& Stefanadis, 2005).

\section{Mechanism of drug-induced QT prolongation}

Psychotropic drugs can affect the QT interval through blockade of ion channels, slowing depolarisation. Slow depolarisation leads to the prolongation of the QRS interval, extending the QT interval. Drugs that block sodium channels in depolarisation produce modest prolongation of the QRS complex and are not thought to be associated with sudden death in individuals without preexisting cardiac disease. Repolarisation, on the other hand, involves sodium, calcium and potassium. The potassium channel most often involved in drug-induced QT abnormalities is the delayed rectifier channel for potassium (inward rectifier $\mathrm{K}^{+}$ channel $\mathrm{I}_{\mathrm{Kr}^{\prime}}$ encoded by the human ether-a-go-gorelated gene (HERG) (DuBuske, 1999). Drugs that block $\mathrm{I}_{\mathrm{Kr}}$ channels (such as thioridazine) can slow repolarisation, which leads to the prolongation of the S-T segment and the T-wave, and therefore the QTc interval. Consequently these drugs can induce torsade de pointes and sudden death in apparently healthy adults (Witchel \& Hancox, 2000).

In animal studies it has been shown that clozapine, haloperidol, pimozide, sertindole and thioridazine block repolarising $\mathrm{I}_{\mathrm{Kr}}$ channels in vitro (Suessbrich et al, 1997; Drolet et al, 1999). In addition, thioridazine and pimozide appear to inhibit calcium channels in rat myocytes, while haloperidol and chlorpromazine block sodium $\left(\mathrm{Na}^{+}\right)$conduction in myocytes (Ogata \& Narahashi, 1989). Furthermore, in isolated spontaneously beating guinea pig Purkinje fibres, chlorpromazine and thioridazine induced early 'after depolarisation' (Studenik et al, 1998), a hypothesised trigger for torsade de pointes (Drici et al, 1998). In an isolated feline heart model, haloperidol, risperidone, sertindole, clozapine and olanzapine produce a dose-dependent prolongation of the QT interval (Drici et al, 1998). Although helpful in providing insight into potential antipsychotic drug-induced QT prolongation in humans in vivo, it should be borne in mind that high doses of antipsychotics were used in these studies.

Drug-drug interaction in the cytochrome P450 (CYP) system is a related hazard, which we discuss in part 2 of this overview (Abdelmawla \& Mitchell, 2006).

\section{What is the risk of sudden death with established ECG changes?}

Early work suggested a simple relationship between degree of QT prolongation and adverse events. Some have suggested that a 5\% increase in baseline risk of arrhythmic events occurs for every $10 \mathrm{~ms}$ increase in the QTc interval (Moss et al, 1991). Although attractive, this is now known to be an oversimplification of a highly complex relationship between the QT interval and cardiovascular risk (Cavero et al, 2000).

Montanez et al (2004) reviewed seven large-scale prospective cohort studies encompassing 36031 individuals from the general population. In people with prior cardiovascular disease, QTc prolongation increased the relative risk of death two- to fourfold, but in the overall population the link between QTC prolongation and cardiovascular mortality/sudden death was inconsistent. Risk factors for sudden cardiac death in healthy people and those with cardiac failure are listed in Box 5. 
Box 5 Risk factors for sudden death

Healthy people

- Repolarisation abnormalities (long QT syndromes)

- Ventricular pre-excitation (Wolff-ParkinsonWhite syndrome)

Those with cardiac failure

- Ischaemic heart disease

- Dilated cardiomyopathy

- Left ventricular systolic dysfunction

- Abnormal signal-averaged ECG

- Non-sustained ventricular tachycardias on Holter monitor recordings

- Reduced heart rate variability

- T-wave alternans

- B-type natriuretic peptide

After Obias-Manno \& Wijetunga (2004); Lane et al (2005)

\section{Adverse events associated with specific antipsychotics}

\section{ECG changes}

Several observational studies suggest that people treated with antipsychotics have a higher than expected rate of ECG changes (Fig. 1). Warner et al (1996) found QTc prolongation in 23\% of 111 inpatients with chronic schizophrenia compared with $2 \%$ of 42 controls.

Reilly et al (2000) compared 339 patients taking antipsychotics (17\% at high or very high doses) without atrial fibrillation or bundle-branch block with a group of 101 healthy controls. In this study QTc prolongation was found in $8 \%$ of those taking antipsychotics and $15 \%$ of those taking antipsychotics and antidepressants in combination. Increasing the antipsychotic dose was associated with increased risk of QTc lengthening.

Kang et al (2000) found that 13 of 54 patients treated with clozapine showed new-onset ECG abnormalities, with a dose-dependent increase in QTc interval. Lin et al (2004) compared ECGs from 412 in-patients taking antipsychotics for schizophrenia with those of 138 controls. Logistic regression analysis showed that significant predictors for QTc prolongation were: older age, female gender and increased doses of clozapine, chlorpromazine, thioridazine and sulpiride. In a prospective study Harrigan et al (2004) randomised 160 patients with psychotic disorders to either haloperidol, thioridazine, ziprasidone, quetiapine, olanzapine or risperidone. Mean QTc intervals were prolonged but did not exceed $500 \mathrm{~ms}$ in any individual, and interestingly were not affected by adding a CYP inhibitor.

Sadanaga et al (2004) examined a cohort of 688 patients prescribed psychotropic drugs and observed a QTc interval >460 ms in $96(14 \%)$. However, they also monitored 97 individuals using a 24-h ECG and estimated the QT intervals at heart rates of 80 and 50 beats $/ \mathrm{min}$. The QT interval at a heart rate of 80 beats/min exceeded $400 \mathrm{~ms}$ in 14 $(15 \%)$ patients and at the heart rate of 50 beats $/ \mathrm{min}$ it exceeded $480 \mathrm{~ms}$ in an additional $12(12 \%)$ patients.

Pooled data from four randomised clinical trials involving 2700 patients did not reveal any ECG abnormalities due to olanzapine (Czekalla et al, 2001).

\section{Serious cardiac events and sudden death Case reports}

Case reports linking antipsychotic drugs and cardiac arrhythmia have appeared for thioridazine (Liberatore \& Robinson, 1984; Donatini et al, 1992), pimozide (Committee on Safety of Medicines, 1990), sulpiride, droperidol, haloperidol (Kriwisky et al, 1990; Jackson et al, 1997), sertindole (Committee on Safety of Medicines, 1999), risperidone (Zarate et al, 1997), ziprasidone (Adolfsson \& Lindblom, 2002) and clozapine (Killian et al, 1999; Hägg et al, 2001). Clozapine has also been linked with potentially fatal myocarditis and cardiomyopathy in physically

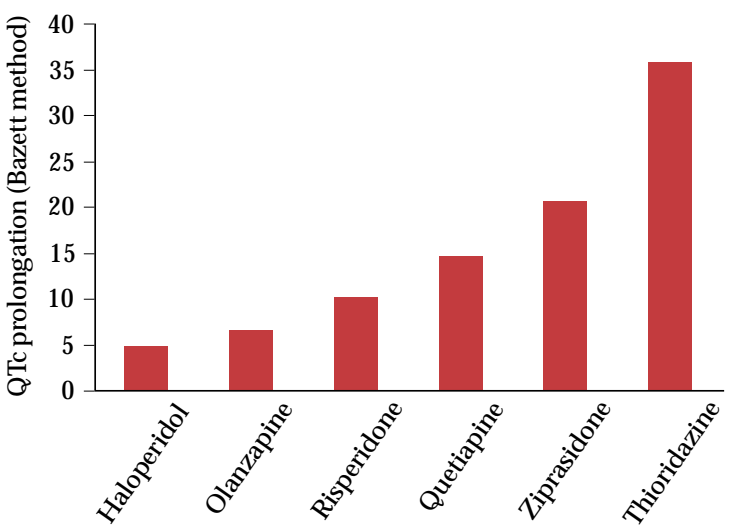

Fig 1 QTc prolongation with common antipsychotic drugs: 183 patients with normal ECGs at baseline were randomized to one of six antipsychotic drugs at maximum daily doses of: ziprasidone $160 \mathrm{mg}$, risperidone $16 \mathrm{mg}$, olanzapine $20 \mathrm{mg}$, quetiapine $750 \mathrm{mg}$, thioridazine $300 \mathrm{mg}$ and haloperidol $15 \mathrm{mg}$ (Data from PsychoPharmacological Drugs Advisory Committee, 2000). 
healthy young adults with schizophrenia. Active myocarditis is suspected as a common precursor of idiopathic dilated cardiomyopathy but is found in a minority of patients with dilated cardiomyopathy (Kopecky \& Gersh, 1987). Confirmatory evidence can be obtained only from endomyocardial biopsy or autopsy.

Since 1980 at least 213 cases of myocarditis in people taking clozapine have been reported in the literature, with at least 50 fatalities (Hägg et al, 2001; Merrill et al, 2005). In some series about half of cases of clozapine-induced myocarditis are fatal, and about a quarter of these people die suddenly.

\section{Overdose studies}

In overdose there may be a dose-response relationship between thioridazine and increasing QTc interval that is not seen for chlorpromazine (Strachan et al, 2004). However, a case series has linked chlorpromazine with ventricular arrhythmias and torsade de pointes (Hoehns et al, 2001). Buckley et al (1995) showed that cardiotoxicity (as indicated by tachycardia, prolonged QT and QTc intervals, widened QRS complex and arrhythmias) appears to be particularly common following thioridazine overdose (Buckley et al, 1995). A review of case reports of overdose of antipsychotics, including the atypicals olanzapine, quetiapine and amisulpride (but not aripiprazole or zotepine), revealed fatal outcomes for nearly all of the typical antipsychotics (Trenton et al, 2003). However, Capel and colleagues found no fatalities in a case series of overdoses of olanzapine, clozapine, risperidone and sulpiride over a 7-month period (Capel et al, 2000).

\section{Epidemiological studies}

Case reports are useful indicators of a potential problem, but estimation of the magnitude of risk requires large-scale experimental or pharmacoepidemiological studies. In a prospective cohort study of 88 in-patients with schizophrenia who had been followed for 10 years, Waddington et al (1998) showed a relationship between increasing number of antipsychotic drugs prescribed concurrently and shorter survival $(R R=2.46)$. Reilly et al $(2000)$ in a study of ECGs from 495 psychiatric patients found evidence of QTc prolongation with thioridazine $(\mathrm{OR}=5.3)$ and droperidol $(\mathrm{OR}=6.7)$. They found a positive dose-response relationship between antipsychotic and QTc prolongation. Risk was elevated if patients were prescribed more than $1000 \mathrm{mg}$ chlorpromazine equivalent per day (the Royal College of Psychiatrists (1997) advises caution with doses above this level). Modai et al (2000) found a fourfold increase in sudden death among 561 individuals taking clozapine $v .4918$ controls and in $75 \%$ of the deaths there was no known medical cause.

Two American teams studied administrative databases (Ray et al, 2001; Hennessy et al, 2002). In the Hennessy et al study, the team compared the relative risk of cardiac arrest or ventricular arrhythmia and death in patients on clozapine, risperidone, and thioridazine with the risk in those on haloperidol. Clozapine and thioridazine were not associated with a higher risk of adverse cardiac events than haloperidol, whereas risperidone was associated with a higher risk of arrhythmic events and all-cause mortality than haloperidol. In addition, there was a dose-dependent relationship between thioridazine and arrhythmic events, particularly at doses of more than $600 \mathrm{mg}$ (Hennessy et al, 2002).

More recently, researchers from The Netherlands (Straus et al, 2004) performed a population-based case-control study of 554 cases of sudden cardiac death. Risk of an event was three times higher in those receiving antipsychotics, six times higher in those receiving butyrophenones (predominantly pipamperone and haloperidol) but not significantly higher in those receiving phenothiazines (predominantly chlorpromazine and thioridazine). The association was also dose- and duration-related and there was a trend for risk to be greater in those under 65 years of age.

Following concerns about droperidol in the USA, Domino et al (1999) evaluated droperidol-associated risk in 45 separate studies. Twenty of these, involving 3339 patients, specifically addressed the frequency of side-effects and no cases of cardiac toxicity or sudden death were reported. Before the black-box warning in the USA, the Food and Drug Administration searched its spontaneous reporting database and the worldwide database for reports of adverse events with droperidol. It found reports of 94 deaths (14 at low dose) and 34 non-fatal cardiac events. However, droperidol was given alone in only 3 fatal cases and 3 non-fatal cases (Kao et al, 2003). The observation of apparently low risk with droperidol and some of the other drugs that clearly prolong the QT interval is yet to be fully explained. One possibility is their degree of penetration into the heart (Titier et al, 2004).

\section{Conclusions}

Sudden death accounts for a small minority of excess deaths in people with mental health difficulties. General physical health, medical comorbidity and risk factors such as obesity, smoking, lack of exercise and diabetes have a substantial impact on accelerated mortality and no 
doubt influence the rate of sudden cardiac death. The role played by antipsychotic medication is not yet fully clarified. Certainly many antipsychotic drugs (including atypicals) cause a dose-dependent QTc prolongation and this is likely to be important in people who take large overdoses. Other ECG changes also occur but these have not been well studied. In large well-conducted population studies the risk conferred by QT prolongation appears to be a modest increase in mortality and sudden death. In large pharmacovigilance studies this is mirrored by an increase in sudden death in patients prescribed antipsychotics. Drugs with greater risk include thioridazine, droperidol, sertindole and ziprasidone; quetiapine, haloperidol, chlorpromazine and olanzapine can be considered of lower risk, given current evidence. The largest modifying variable for antipsychotic-induced sudden death is established (or occult) cardiovascular disease. A further consistent risk factor is the cumulative dose of antipsychotic (including polypharmacy) (Waddington et al, 1998; Hennessy et al, 2002). Clinically, this is a serious concern. Ganguly et al (2004) found the rate of antipsychotic combinations in 31435 people with schizophrenia to be $40 \%$. Comorbid physical illness should also not be underestimated: $16 \%$ of patients with schizophrenia have at least one medical condition associated with QT prolongation (Kalsekar et al, 2003 ) and up to $74 \%$ have a chronic medical condition of some type (Jones et al, 2004).

In part 2 of this overview (Abdelmawla \& Mitchell, 2006) we will discuss monitoring of people newly prescribed antipsychotics and prevention of antipsychotic-induced sudden death.

\section{Declaration of interest}

None.

\section{References}

Abdelmawla, N. \& Mitchell, A. J. (2006) Sudden cardiac death and antipsychotic drugs. Part 2: Monitoring and prevention. Advances in Psychiatric Treatment, 12, in press.

Adolfsson, R. \& Lindblom, Y. (2002) Cardiac conduction disturbances in two patients receiving ziprasidone monotherapy. Schizophrenia Research, 53(3) (suppl.), 162.

Al-Khatib, S. M., LaPointe, N. M., Kramer, J. M., et al (2003) What clinicians should know about the QT interval. JAMA 289, 2140-2127.

Allebeck, P. \& Wistedt, B. (1986) Mortality in schizophrenia. A ten year follow-up based on the Stockholm County inpatient register. Archives of General Psychiatry, 43, 650-653.

Botstein, P. (1993) Is QT interval prolongation harmful? A regulatory perspective. American Journal of Cardiology, 72, 50B-52B.

Brown, S., Barraclough, B. \& Inskip, H. (2000) Causes of the excess mortality of schizophrenia. British Journal of Psychiatry, 177, 212-217.

Buckley, N. A., Whyte, I. M. \& Dawson, A. H. (1995) Cardiotoxicity more common in thioridazine overdose than with other neuroleptics. Journal of Toxicology. Clinical Toxicology, 33, 199-204.

Capel, M. M., Colbridge, M. G. \& Henry, J. A. (2000) Overdose profiles of new antipsychotic agents. International Journal of Neuropsychopharmacology, 3, 51-54.

Cavero, I., Mestre, M., Guillon, J. M., et al (2000) Drugs that prolong QT interval as an unwanted effect: assessing their likelihood of inducing hazardous cardiac dysrhythmias. Expert Opinion in Pharmacotherapy, 1, 947-973.

Chugh, S. P., Kelly, K. L. \& Titus, J. L. (2000) Sudden cardiac death with apparently normal heart. Circulation, 102, 649654 .

Citrome, L., Brook, S., Warrington, L., et al (2004) Ziprasidone versus haloperidol for the treatment of agitation. Annals of Emergency Medicine, 44(4) (suppl.), S22.

Committee on Safety of Medicines (1990) Cardiotoxic effects of pimozide. Current Problems in Pharmacovigilance, 29, 1.

Committee on Safety of Medicines (1996) Drug-induced prolongation of the QT interval. Current Problems in Pharmacovigilance, 22, 2.

Committee on Safety of Medicines (1998) Suspension of Availability of Serdolect (Sertindole). London: Department of Health.

Committee on Safety of Medicines (1999) Suspension of availability of sertindole (Serdolect) due to reports of sudden cardiac death. Current Problems in Pharmacovigilance, 25, 1.

Connolly, M. \& Kelly, C. (2005) Lifestyle and physical health in schizophrenia. Advances in Psychiatric Treatment, 11, 125-132.

Curkendall, S. M., Mo, J., Glasser, D. B., et al (2004) Cardiovascular disease in patients with schizophrenia in Saskatchewan Canada. Journal of Clinical Psychiatry, 65, 715-720.

Czekalla, J., Beasley, C. M., Dellva, M. A., et al (2001) Analysis of the QTc interval during olanzapine treatment of patients with schizophrenia and related psychosis. Journal of Clinical Psychiatry, 62, 191-198.

de Bruyne, M. C., Hoes, A. W., Kors, J. A., et al (1999) Prolonged QT interval predicts cardiac and all-cause mortality in the elderly: the Rotterdam Study. European Heart Journal, 20, 278284.

Dershwitz, M. (2002) Droperidol: should the black box be light gray? Journal of Clinical Anesthesia, 14, 598-603.

Dilaveris, P. E. \& Stefanadis, C. I. (2005) Molecular predictors of drug-induced prolongation of the QT interval. Current Medicinal Chemistry - Cardiovascular and Hematological Agents, 3, 105-118.

Domino, K., Anderson, E., Polissar, N., et al (1999) Comparative efficacy and safety of ondansetron, droperidol, and metoclopramide for preventing postoperative nausea and vomiting: a meta-analysis. Anaesthetics and Analgesia, 88, 1370-1379.

Donatini, B., LeBlaye, I. \& Krupp, P. (1992) Transient cardiac pacing is insufficiently used to treat arrhythmia associated with thioridazine. Cardiology, 81, 340-341.

Drici, M. D., Wang, W. X., Liu, X., et al (1998) Prolongation of QT interval in isolated feline hearts by antipsychotic drugs. Journal of Clinical Psychopharmacology, 18, 477-481.

Drolet, B., Vincent, F., Rail, J., et al (1999) Thioridazine lengthens repolarization of cardiac ventricular myocytes by blocking the delayed rectifier potassium current. Journal of Pharmacology and Experimental Therapeutics, 288, 1261-1268.

DuBuske, L. M. (1999) Second-generation antihistamines: the risk of ventricular arrhythmias. Clinical Therapeutics, 21, 281295.

Engdahl, J., Holmberg, M., Karlson, B. W., et al (2002) The epidemiology of out-of-hospital 'sudden' cardiac arrest. Resuscitation, 52, 235-245.

Ganguly, R., Kotzan, J. A., Miller, L. S., et al (2004) Prevalence, trends, and factors associated with antipsychotic polypharmacy among Medicaid-eligible schizophrenia patients, 1998-2000. Journal of Clinical Psychiatry, 65, 1377-1388.

Glassman, A., H. \& Bigger Jr., J. T. (2001) Antipsychotic drugs: prolonged QTc interval, torsade de pointes, and sudden death. American Journal of Psychiatry, 158, 1774-1782.

Green, L. K. (1988) Sudden death and prolonged antipsychotic drugs. American Journal of Clinical Psychiatry, 90, 501. 
Hägg, S., Spigset, O., Bate, A., et al (2001) Myocarditis related to clozapine treatment. Journal of Clinical Psychopharmacology, 21, 382-388.

Harrigan, E. P., Miceli, J. J., Anziano, R., et al (2004) A randomized evaluation of the effects of six antipsychotic agents on QTc, in the absence and presence of metabolic inhibition. Journal of Clinical Psychopharmacology, 24, 62-69.

Hennessy, S., Bilker, W. B., Knauss, J. S., et al (2002) Cardiac arrest and ventricular arrhythmia in patients taking antipsychotic drugs: cohort study using administrative data. $B M J, 325,1070$

Hewer, W. \& Rossler, W. (1997) Mortality among inpatients with functional psychiatric disorder. Fortschritte Der Neurologie, Psychiatrie, 65, 171-181.

Hoehns, J, D., Stanford, R. H., Geraets, D. R., et al (2001) Torsades de pointes associated with chlorpromazine: case report and review of associated ventricular arrhythmias. Pharmacotherapy, 21, 871-883.

Jackson, T., Ditmanson, L. \& Phibbs, B. (1997) Torsades de pointes and low-dose oral haloperidol. Achives of Internal Medicine, 157, 2013-2015.

Jones, D. R., Macias, C., Barreira, P. J., et al (2004) Prevalence, severity, and co-occurrence of chronic physical health problems of persons with serious mental illness. Psychiatric Services, 55, 1250-1257.

Jusic, N. \& Lader, M. (1994) Post-mortem antipsychotic drug concentrations and unexplained deaths. British Journal of Psychiatry, 165, 787-791.

Kalsekar, I. D., Makela, E. H. \& Moeller, K. E. (2003) Analysis of West Virginia Medicaid claims data for the prevalence of medical conditions and use of drugs likely to cause QT prolongation in patients with schizophrenia. Current Therapeutic Research - Clinical and Experimental, 64, 538-550.

Kang, U. G., Kwon, J. S., Ahn, Y. M., et al (2000) Electrocardiographic abnormalities in patients treated with clozapine. Journal of Clinical Psychiatry, 61, 441-446.

Kao, L. W., Kirk, M. A., Evers, S. J., et al (2003) Droperidol, QT prolongation, and sudden death: what is the evidence? Annals of Emergency Medicine, 41, 546-558.

Killian, J. G., Kerr, K., Lawrence, C., et al (1999) Myocarditis and cardiomyopathy associated with clozapine. Lancet, 354, 1841-1845.

Kopecky, S. L. \& Gersh, B. J. (1987) Dilated cardiomyopathy and myocarditis: natural history, etiology, clinical manifestations, and management. Current Problems in Cardiology, 12, 569-647.

Kriwisky, M., Perry, G. Y., Tarchitsky, D., et al (1990) Haloperidolinduced torsades de pointes. Chest, 98, 482-484.

Lane, R. E., Cowie, M. R. \& Chow, A. W. C. (2005) Prediction and prevention of sudden cardiac death in heart failure. Heart, 91, 674-680.

Liberatore, M. A. \& Robinson, D. S. (1984) Torsades de pointes: a mechanism for sudden death associated with neuroleptic drug therapy? Journal of Clinical Psychopharmacology, 4, 143-146.

Lin, C. H., Chen, M. C., Wang, S. Y., et al (2004) Predictive factors for QTc prolongation in schizophrenic patients taking antipsychotics. Journal of the Formosan Medical Association, 103, 437-441.

Liperoti, R., Gambassi, G., Lapane, K. L., et al (2005) Conventional and atypical antipsychotics and the risk of hospitalization for ventricular arrhythmias or cardiac arrest. Archives of Internal Medicine, 165, 696-701.

Malik, M. \& Camm, A. J. (2001) Evaluation of drug-induced QT interval prolongation. Drug Safety, 24, 323-351.

Maron, B. J. (2003) Sudden death in young athletes. New England Journal of Medicine, 349, 1064-1075.

Medicines and Healthcare Products Regulatory Agency (2000) MHRA (Medicines) Restricts the Use of Thioridazine. MHRA Press Release 2000/0734. London: MHRA.

Mehtonen, O. P., Aranki, K., Malkonen, L., et al (1991) A survey of sudden death associated with the use of antipsychotics or antidepressant drugs: 49 cases in Finland. Acta Psychiatrica Scandinavica, 84, 58-64.

Merrill, D. B., Dec, G. W. \& Goff, D. C. (2005) Adverse cardiac effects associated with clozapine. Journal of Clinical Psychopharmacology, 25, 32-41.
Modai, I., Hirschmann, S., Rava, A., et al (2000) Sudden death in patients receiving clozapine treatment. A preliminary investigation. Journal of Clinical Psychopharmacology, 20, 325-327.

Montanez, A., Ruskin, J. N., Hebert, P. R., et al (2004) Prolonged QTc interval and risks of total and cardiovascular mortality and sudden death in the general population. A review and qualitative overview of the prospective cohort studies. Archives of Internal Medicine, 164, 943-948.

Montout, C., Casadebaig, F., Lagnaoui, R., et al (2002) Neuroleptics and mortality in schizophrenia: prospective analysis of deaths in a French cohort of schizophrenic patients. Schizophrenia Research, 57, 147-156.

Morganroth, J. (1993) Relations of QTc prolongation on the electrocardiogram to torsades de pointes: definitions and mechanisms. American Journal of Cardiology, 72, 10B-13B.

Moss, A. J. (1993) Measurement of the QT interval and the risk associated with QTc interval prolongation: a review. American Journal of Cardiology, 72, 23B-25B.

Moss, A. J., Schwartz, P. J., Crampton, R. S., et al (1991) The long QT syndrome: prospective longitudinal study of 328 families. Circulation, 84, 1136-1144.

Myerberg, R. J. (1997) Cardiac arrest and sudden cardiac death. In Heart Disease: A Text Book of Cardiovascular Medicine (ed. E Braunwald), pp. 742-779. New York: WB Saunders.

National Alliance for the Mentally Ill (1998) Cries of Anguish: A Summary of Reports of Restraints and Seclusions Abuse Received Since the October 1998 Investigation by the Hartford Courant. Arlington, VA: National Alliance on Mental Illness. http://www.nami.org/update/hartford.html

National Institute for Clinical Excellence (2004) The Short-term Management of Disturbed (Violent) Behaviour in Adult Psychiatric Inpatient Settings. First Consultation document. London: NICE.

Nose, M., Barbui, C. \& Tansella, M. (2003) How often do patients with psychosis fail to adhere to treatment programmes? A systematic review. Psychological Medicine, 33, 1149-1160.

Obias-Manno, D. \& Wijetunga, M. (2004) Risk stratification and primary prevention of sudden cardiac death. AACN Clinical Issues, 15, 404-418.

O'Brien, P. \& Oyebode, F. (2003) Psychotropic medication and the heart. Advances in Psychiatric Treatment, 9, 414-423.

Ogata, N. \& Narahashi, T. (1989) Block of sodium channels by psychotropic drugs in single guinea-pig cardiac myocytes. British Journal of Pharmacology, 97, 905-913.

Ösby, U., Correia, N., Brandt, L., et al (2000) Mortality and causes of death in schizophrenia in Stockholm County, Sweden. Schizophrenia Research, 45, 21-28.

Priori, S. G., Alliot, E., Blomstrom-Lundqvit, C., et al (2001) Task Force on Sudden Cardiac Death of the European Society of Cardiology. European Heart Journal, 22, 1374-1450.

PsychoPharmacological Drugs Advisory Committee (2000) Conclusion. In FDA Background on Zeldox ${ }^{T M}$ (Ziprasidone Hydrochloride Capsules). Pfizer, Inc. Rockville, MD: Food and Drug Administration. http://www.fda.gov/ohrms / dockets/ac/00/backgrd/3619b1b.pdf

Rautaharju, P. M. \& Zhang, Z. M. (2002) Linearly scaled, rateinvariant normal limits for QT interval: eight decades of incorrect application of power functions. Journal of Cardiovascular Electrophysiology, 12, 1211-1218.

Ray, W. A., Meredith, S., Thapa, P. B., et al (2001) Antipsychotics and the risk of sudden cardiac death. Archives of General Psychiatry, 58, 1161-1167.

Reilly, J. G., Ayis, S. A., Ferrier, I. N., et al (2000) QTc-interval abnormalities and psychotropic drug therapy in psychiatric patients. Lancet, 355, 1048-1052.

Reilly, J. G., Ayis, S. A., Ferrier, I. N., et al (2002) Thioridazine and sudden unexplained death in psychiatric in-patients. British Journal of Psychiatry, 180, 515-522.

Reinert, R. E. \& Hermann, C. G. (1960) Unexplained deaths during chlorpromazine therapy. Journal of Nervous and Mental Disease, 131, 435-442.

Royal College of Psychiatrists (1997) The Association between Antipsychotic Drugs and Sudden Death. Report of the Working Group of the Royal College of Psychiatrists' Psychopharmacology SubGroup (Council Report CR57). London: Royal College of Psychiatrists. 
Sadanaga, T., Sadanaga, F., Yao, H., et al (2004) Abnormal QT prolongation and psychotropic drug therapy in psychiatric patients: Significance of bradycardia-dependent QT prolongation. Journal of Electrocardiology, 37, 267-273.

Saz, P. \& Dewey, M. E. (2001) Depression, depressive symptoms and mortality in persons aged 65 and over living in the community: a systematic review of the literature. International Journal of Geriatric Psychiatry, 16, 622-630.

Spector, P. S. (2005) Diagnosis and management of sudden cardiac death. Heart, 91, 408-413.

Strachan, E. M., Kelly, C. A. \& Bateman, D. N. (2004) Electrocardiogram and cardiovascular changes in thioridazine and chlorpromazine poisoning. European Journal of Clinical Pharmacology, 60, 541-545.

Straus, S. M. J. M., Bleumink, G. S., Dieleman, J. P., et al (2004) Antipsychotics and the risk of sudden cardiac death. Archives of Internal Medicine, 164, 1293-1297.

Studenik, C., Lemmens-Gruber, R. \& Heistracher, P. (1998) Proarrhythmic effects of antidepressants and neuroleptic drugs on isolated, spontaneously beating guinea pig Purkinje fibres. European Journal of Pharmacological Sciences, 7, 113-118.

Suessbrich, H., Schonherr, R., Heinemann, S. H., et al (1997) The inhibitory effect of the antipsychotic drug haloperido on HERG potassium channels expressed in Xenopus oocytes. British Journal of Pharmacology, 120, 968-974.

Taylor, D. M. (2003) Antipsychotics and QT prolongation. Acta Psychiatrica Scandinavia, 107, 85-95.

Titier, K., Canal, M., Deridet, E., et al (2004) Determination of myocardium to plasma concentration ratios of five antipsychotic drugs: comparison with their ability to induce arrhythmia and sudden death in clinical practice. Toxicology and Applied Pharmacology, 199, 52-60.

Titier, K., Girodet, P. O., Verdoux, H., et al (2005) Atypical antipsychotics: from potassium channels to torsade de pointes and sudden death. Drug Safety, 28, 35-51.

TREC Collaborative Group (2003) Rapid tranquillisation for agitated patients in emergency psychiatric rooms: a randomised trial of midazolam versus haloperidol plus promethazine. $B M J, 327,708-711$.

Trenton, A. J., Currier, G. W, \& Zwemer, F. L. (2003) Fatalities associated with therapeutic use and overdose of atypical antipsychotics. CNS Drugs, 17, 307-324.

Waddington, J. L., Youssef, H. A. \& Kinsella, A. (1998) Mortality in schizophrenia. Antipsychotic polypharmacy and absence of adjunctive anticholinergics over the course of a 10-year prospective study. British Journal of Psychiatry, 173, 325-329.

Warner, J. P., Barnes, T. R. E. \& Henry, J. A. (1996) Electrocardiographic changes in patients receiving neuroleptic medication. Acta Psychiatrica Scandinavica, 93, 311-313.

Welch, R. \& Chue, P. (2000) Antipsychotic agents and QT changes. Journal of Psychiatry and Neuroscience, 25, 154-160.

Witchel, H. J. \& Hancox, J. C. (2000) Familial and acquired long QT syndrome and the cardiac rapid delayed rectifier potassium current. Clinical Experimental Pharmacology and Physiology 27, 753-766.

Zarate, C. A., Baldessarini, R. J., Siegel, A. J., et al (1997) Risperidone in the elderly: a pharmacoepidemiologic study. Journal of Clinical Psychiatry, 58, 311-317.

Zareba, W. \& Moss, A. J. (2003) QT interval and its drug-induced prolongation. In Cardiac Repolarization: Bridging Basic and Clinical Science (eds I. Gussak, C. Antzelevitch, S. C. Hammill, et al), pp. 311-328. Totowa, NJ: Humana Press.

\section{MCQs}

1 As regards torsade de pointes and sudden cardiac death:

a all drugs that prolong the QTc interval produce torsade de pointes and sudden death

b all drugs known to cause torsade de pointes block the HERG potassium channels

c torsade de pointes is a form of atrial fibrillation

d most cases of torsade de pointes are fatal

e torsade de pointes must be managed by cardiac pacing.

2 As regards the QT interval:

a Bazett's formula measures the QT interval

b QT interval represents atrial depolarisation

c vagal stimulation prolongs the unadjusted QT interval

d QT prolongation on automated readings should be checked manually

e shortening of QT interval is found in hypercalcaemia.

3 Epidemiological studies of antipsychotic drugs and sudden cardiac death show:

a a dose-response relationship for certain antipsychotics

b that the risk of antipsychotic-induced sudden death is highest in patients taking depot antipsychotics

c that the risk of antipsychotic-induced sudden death is small in those without cardiac disease

d that sudden death typically occurs in people under the age of 30 years

e that sudden death does not occur in people with depressive disorder treated with atypical antipsychotics.

4 Risk factors for torsade de pointes include:

a male gender

b hypokalaemia

c congenital long-QT syndrome

d heart failure

e hypomagnesaemia.

\section{MCQ answers}

1

2

a $\mathrm{F}$

\section{2}

b $\mathrm{T}$

a $\mathrm{F}$

b F

c $\mathrm{F}$

c $\mathrm{T}$

d F

d $\mathrm{T}$

e $F$

e $\mathrm{T}$ 3

a $\mathrm{T}$

b F

a $\mathrm{F}$

c $\mathrm{T}$

d F

b $\mathrm{T}$

c $\mathrm{T}$

d $\mathrm{T}$

e $\mathrm{T}$ 